\title{
Texture perception in sighted and blind observers
}

\author{
MORTON A. HELLER \\ Winston-Salem State University, Winston-Salem, North Carolina
}

\begin{abstract}
The purpose of the present study was to evaluate the utility of visual imagery for texture perception. In Experiment 1, sighted, early-blind, and late-blind observers made relative smoothness judgments of abrasive surfaces using active or passive touch. In Experiment 2, subjects compared vision and touch in the accuracy of smoothness detection, using a broad range of textures, including very fine surfaces. No differences appeared between the sighted and the blind, and it did not matter if touch were active or passive. Vision and touch showed similar performance with relatively coarse textures, but touch was superior to vision for much finer surface textures. The results were consistent with the notion that visual coding of tactual stimuli is not advantageous (or necessary) for texture perception, since touch may hold advantages for the detection of the smoothness of surfaces.
\end{abstract}

The present study was directed toward an evaluation of the necessity of visual imagery for texture perception. Some researchers have claimed that visual images are necessary for tactual perception of form by sighted individuals (e.g., Pick, 1974). There are numerous reports of the benefits of visual imagery for memory in the sighted (e.g., Christian, Bickley, Tarka, \& Clayton, 1978) and the late blind (e.g., Warren, 1984). In a number of spatial tasks, the sighted and late blind have performed at similar levels, but the congenitally blind have shown deficiencies. It is usually assumed that the late blind maintain the use of visual imagery and that this helps them in form perception (Worchel, 1951), mobility, and other tasks dependent upon spatial skills (Millar, 1975, 1976). Unfortunately, the data are not that clear-cut, since Bailes and Lambert (1986) recently reported no difference between congenitally blind and late-blind subjects in a form recognition and memory task. However, they did find slightly higher performance for the sighted controls and late blind in recognition of simple two-dimensional patterns in their 0-sec delay condition. Furthermore, the blind may have a better understanding of the vertical than do blindfolded sighted subjects when exposed to tilt: Bitterman and Worchel (1953) found that sighted observers showed greater disorientation than blind persons when

Preparation of this report and the research were supported by National Institutes of Health MBRS Grant 2 SO6-08040-16. I wish to thank Kim Nesbitt and Danette Scrofano for assistance with data collection and statistical analyses. Susan Lederman provided helpful comments on an earlier version of this manuscriipt. Some of the results of these experiments were presented at the annual meeting of the Eastern Psychological Association, Buffalo, NY, April, 1988. I am grateful to the participants and to the staff and administrators at the Industries for the Blind Workshops in Greensboro and Winston-Salem, and at the Rehabilitation Center at the Lion's Club Facility in Raleigh, including Ward Butler, Brad Rivers, Delmer Wall, Derek Davis, Pat Meekins, and Paul Roland. Address reprint requests to M. A. Heller, Department of Psychology, Winston-Salem State University, Winston-Salem, NC 27110. subjected to tilt. Although the benefits of visual imagery are likely to be pronounced in form perception, it is not known whether visualization aids in texture judgments.

One would expect that observers would tend to visualize for stimulus dimensions in which vision provides superior performance, as in form perception. Visual imagery might be most helpful when images of movement can reliably serve to code the stimulus dimensions of patterns. Moreover, it is possible that the benefits of visual imagery in the sighted and late blind are tied to a history of sight of hand movements during the exploration of shapes. Individuals might store memories in the form of visual representations of movement (Heller, 1985). If this is true, tactile tasks that are independent of complex motor sequences might not rely on visual imagery. Furthermore, one might expect visualization only if vision were superior to touch for information pickup. This may not be the case for texture perception, since similar performance has been reported for the two modalities in judgments of abrasive surfaces (Heller, 1982; Jones \& O'Neal, 1985; Lederman \& Abbott, 1981). Bjorkman (1967), however, reported that visual texture judgments were less variable than tactual judgments.

The active/passive touch issue is intimately tied to questions involving comparisons between the sighted and the blind. Jones (1975) proposed that movements may provide a link between the senses. According to this view, differences between the sighted and blind could accrue from differential experience with movement, rather than differences in visual experience. One might expect differences between the sighted and congenitally blind if fine manual dexterity were involved in a task and if benefits derived from active touch. According to the motor view of intersensory integration (Jones, 1975), any possible differences between the sighted and early blind would most likely occur for active touch. Touch is passive (Gibson, 1962) when the observer makes no voluntary move- 
ments and information is imposed on a stationary individual. According to Gibson, passive touch is not ecologically valid, and leads to subjective experiences. Active touch, where the observer makes movements to purposively obtain information about the world, was presumed to lead to superior information pickup (Heller, 1980a, 1980b, 1984, 1986a, 1986b). Katz (see Krueger, 1982) claimed that passive touch was insufficient for the apprehension of form. However, there are some occasions in which passive movements may lead to satisfactory or even superior form perception (Heller, 1986b; Heller \& Boyd, 1984; Magee \& Kennedy, 1980). Active touch is often deficient when observers encounter problems with movement control (Heller, 1986b; Heller \& Boyd, 1984).

It is possible that self-produced movement may not be essential for texture perception. Lederman (1981) reported no difference in magnitude estimates of roughness for active or passive touch. Lamb (1983) also reported no difference between active and passive tactual judgments of texture. In a more recent paper, however, Lederman (1983, Experiment 2) found a nonsignificant effect of perceptual mode, but a marginally significant interaction between perceptual mode and rate. Perceived roughness was lower for passive touch at the faster rate of stimulus movement. It is not known if this interaction is important, because it accounted for a negligible percentage of the overall variance attributable to treatment effects.

Experiment 1 was performed to determine whether the sighted and late blind would outperform the early blind in tactual texture perception. If visual experience were important for such perception, one would expect higher performance in observers who had seen and presumably had the benefits of visual imagery. Based on the assumption that self-produced movement might be essential for accurate texture perception, active touch should produce superior smoothness judgments. Passive texture judgments also permitted a "fair" comparison between tactual perception in the sighted and blind, since any differences that might appear could not be attributed to differential motor skills. A second experiment compared vision and touch in relative smoothness judgments, but with a wider range of stimuli and much finer abrasives than in any prior research.

\section{EXPERIMENT 1}

In Experiment 1, sighted, early-blind, and late-blind observers made relative smoothness judgments with either active or passive touch. The superiority of the sighted in texture judgments would implicate the benefits of visual imagery.

\section{Method}

Subjects. Ten sighted controls $(M$ age $=35.6$ years; range $=$ 20-55; 7 males and 3 females), including students, faculty, and staff, were recruited on an undergraduate campus. The 10 late-blind subjects were employees at Industries for the Blind in Greensboro and Winston-Salem $(M$ age $=45.7$ years; range $=32-53 ; 9$ males and 1 female). Ten early-blind subjects ( $M$ age $=37.5$ years; range
$=24-50 ; 7$ males and 3 females) were recruited from the same locations as the late blind, as well as from the Lion's Club Industries for the Blind in Raleigh and the general communities of Winston-Salem and Raleigh; all were blind from birth, with the exception of one person who lost his sight at 3 months. Four of the early-blind individuals had retrolental fibroplasia, whereas the rest lost sight because of congenital abnormalities of the optic nerve, cataracts, and other causes. The early-blind subjects were quite varied in background, and included several individuals with college experience, some college graduates, and one university professor. None of the blind subjects perceived form or hand movements, but many had minimal light perception.

Stimuli. The stimuli were $5-\mathrm{cm}^{2}$ aluminum oxide abrasive papers (Norton Adolox Nofil), with grit values of 80, 100, 120, 150, 180, $220,240,280,320$, and 400 . The grit numerical value designates the number of openings per inch in a screen used to sort the abrasives (Stevens \& Harris, 1962). Grit number refers to the reciprocal of the diameter of the openings in the screen. Larger numbers describe finer textures and smaller particles. The stimuli were arranged in pairs of adjacent grit values on rectangular Masonite panels, with approximately $3 \mathrm{~mm}$ between the squares of abrasive paper; their left-right position was assigned randomly. There were eight series: 80 and 100,100 and 120 , and so on, to 320 and 400 . The 280 grit sample was not used as the smoother choice, since prior research (Heller, 1982) showed anomalous responses to that texture; that is, subjects did not consistently rate that surface smoother than $\mathbf{2 4 0}$ grit paper. It is not obvious why this obtained, but there are other reports of this with $\mathbf{2 8 0}$ grit abrasives (Bjorkman, 1967; Lederman \& Abbott, 1981). Five other stimulus sets were prepared, for a total of 48 trials per subject. The stimuli were mounted with pressure-sensitive adhesive and were frequently changed. A Masonite baffle was used to block sight of tactual exploration.

Design and Procedure. The experiment took the form of a mixedfactor analysis of variance. The factors were visual status (sighted, early blind, or late blind) and perceptual mode (active or passive touch), with repeated measures on mode of touch. ${ }^{1}$ The subjects were required to choose the "smoother" of two pieces of abrasive paper. ${ }^{2}$ Individuals used the preferred index finger. Time limits were not imposed, and feedback was not given. Half of the subjects began with active touch for half of the trials, and half began with passive touch. They then employed the other mode of touch. In the passive condition, observers extended the final digit of the index finger over the edge of a foam-covered shelf (see Heller, 1986a) and kept the finger motionless. In addition, the stable finger was fixed in place with masking tape. The experimenter pressed the stimuli up against the motionless finger while moving the stimuli laterally, back-and-forth and from side-to-side, until the subject named one as smoother. Lateral motion has been identified as an optimal strategy for texture perception (Lederman \& Klatzky, 1987). Moderate (relatively low) force levels were used, and the stimuli were moved at a constant, slow rate (approximately $2 \mathrm{~cm}$ per $\mathrm{sec}$ ). Low force levels were used to minimize any lateral displacement of the subjects' fingers. The subjects were able to request increased force levels, but none did. ${ }^{3}$

\section{Results and Discussion}

Performance was very similar for the sighted and the blind (see Table 1). A mixed-factor analysis of variance indicated that the effect of visual status was nonsignificant $(F<1)$, that it did not matter if subjects were active or passive $[F(1,27)=1.4, p>.05]$, and that the interaction was also nonsignificant $(F<1)$. The early blind did not show inferior performance to that of the sighted or late blind; in fact, their score with active touch was slightly higher. ${ }^{4}$ The equivalent performance under 
Table 1

Mean Number Correct and Standard Deviation for Sighted, Late-Blind, and Early-Blind Observers with Active and Passive Touch

\begin{tabular}{lcccc} 
& \multicolumn{4}{c}{ Tactual Mode } \\
\cline { 2 - 5 } & \multicolumn{2}{c}{ Active } & \multicolumn{3}{c}{ Passive } \\
\cline { 2 - 5 } Visual Status & $M$ & 2.85 & 19.8 & $S D$ \\
\hline Sighted & 19.9 & 2.06 & 20.3 & 2.04 \\
Late Blind & 20.5 & 1.73 & 19.8 & 1.85 \\
Early Blind & 21.1 & & & 1.99 \\
\hline
\end{tabular}

Note-The maximum score possible was 24 for each mode of touch.

conditions of active or passive touch is consistent with earlier reports (Lamb, 1983; Lederman, 1981, 1983). Active movement may play a greater role in form perception and spatial cognition, or in more difficult texture discrimination tasks when visual guidance is available (Heller, 1982). ${ }^{5}$

The results of Experiment 1 show that visual imagery is not necessary for texture perception. There was no evidence that subjects recoded tactual impressions into visual images, since sighted and late-blind subjects did not perform any better than the early blind. These results with a texture task are in striking contrast with the frequently reported advantages of visual experience for form perception. It should be noted that both the sighted and the blind are relatively familiar with the use of touch for texture judgments. The early blind frequently make use of touch to examine textured surfaces, and almost all of them in the present study were proficient braille readers. Millar $(1978,1985)$ suggested that braille identification is related to the perception of dot density, and can be considered a sort of texture task. Both vision and touch can be used successfully to perceive texture, and there is probably little reason to expect that visualization would be used under circumstances in which touch is very reliable (see Heller, 1982; Lederman \& Abbott, 1981). An additional experiment compared vision and touch in texture perception, since earlier studies used rather limited ranges of stimuli. The world of texture is extremely complex and rich, and it was thought that a broader range of textures might shed new light on the relative adequacy of the senses of sight and touch.

\section{EXPERIMENT 2: THE ADVANTAGE OF TOUCH}

Experiment 2 was performed to compare vision and touch in the accuracy of texture judgments. It was expected that they would show similar performance levels with relatively coarse stimuli (Heller, 1982; Lederman \& Abbott, 1981), but it was not known if one sense would prove superior with very fine surfaces (see Welch \& Warren, 1986).

\section{Method}

Subjects. Twenty-four sighted subjects participated in Experiment 2; half were male and half were female. All subjects in the vision condition had vision that was normal or corrected to normal (as tested by a Snellen chart).

Stimuli and Apparatus. The apparatus was similar to that of Experiment 1 , but the stimuli were very different. Japanese abrasive sharpening stones (Matsunaga/King brand waterstones) were selected, since they vary in grit value from coarse (220 grit) to more than 6,000 grit (extremely fine). The grit values chosen for twoalternative relative smoothness judgments were $220,250,800$, $1,000,1,200,4,000$, and 6,000 . There were six series, three coarse and three fine. The coarse series included 220 and 250, 250 and 800 , and 800 and 1,000 grit stones ${ }^{6}$; the fine series included 1,000 and $1,200,1,200$ and 4,000, and 4,000 and 6,000 grit stones. Prior to the experiment, the smoothest stones $(1,200,4,000$, and 6,000 grit) were "trued" with a Nagura abrasive stone. This "truing" consisted of nubbing the surfaces of the abrasive with a Nagura stone to remove any irrelevant surface undulations; subsequently, the stones were rinsed with water and dried. (Nagura stones are manufactured to smooth fine Japanese waterstones.)

Four sets of random arrangements were prepared, so that each subject was exposed to 24 trials; each set consisted of a random arrangement of the six series. The correct choice appeared equally often on the left and right side. The stones were covered in white poster board, with a $4 \times 8 \mathrm{~cm}$ opening through which the surfaces could be viewed or touched. Overhead fluorescent lighting was supplemented by light from a 75 -W incandescent lamp at an oblique orientation (45 $5^{\circ}$ approximately $50 \mathrm{~cm}$ distant from the stimuli). Side lighting was provided to maximize visual texture information. As in Experiment 1, acoustically isolating headphones were used to minimize auditory texture cues.

Design and Procedure. The experiment was a mixed-factor analysis of variance. The factors were modality (vision or touch) and range of grit values (fine or coarse), with repeated measures on the range of grit values. All subjects were told they should choose the surface that was "smoother." The procedure was similar to the active condition in Experiment 1, and feedback was not given. All tactual observers first cleaned their preferred index fingers with alcohol and paper towels. In addition, individuals were required to dry their fingers on paper towels before each trial (for touch). Touch subjects tapped their choices, whereas vision observers were asked to point to the surfaces they thought were smoother. Vision subjects were encouraged to move their heads about to optimize viewing conditions. In addition, they were told they could bring their eyes as close to the surfaces as they wished, but were denied contact.

\section{Results and Discussion}

The subjects performed much better with touch $(92.4 \%$ correct overall) than with vision $(68.4 \%$ correct). A mixed-factor analysis of variance showed a significant effect of perceptual mode $[F(1,22)=65.6, p<.001]$, a significant effect of the range of smoothness of the stones $[F(1,22)=88.1, p<.001]$, and a significant interaction between the modality and range of textures $[F(1,22)=$

Table 2

Mean Number Correct and Standard Deviation for Vision and Touch with Coarse and Fine Abrasives

\begin{tabular}{cccccc}
\hline & \multicolumn{4}{c}{ Range of Stimuli } \\
\cline { 2 - 6 } Perceptual & \multicolumn{2}{c}{ Coarse } & $S D$ & & \multicolumn{3}{c}{ Fine } \\
\cline { 2 - 6 } Modality & $M$ & $S D$ & $S D$ \\
\hline Vision & 11.08 & 1.08 & 5.33 & 1.5 \\
Touch & 11.58 & 0.51 & 10.58 & 1.56 \\
\hline
\end{tabular}

Note-The maximum score possible for each range of stimuli was 12 . 
$43.6, p<.001]$. Table 2 shows the means and standard deviations for touch and vision. It should be noted that there is little difference between vision and touch for coarser stimuli (through 1,000 grit), a result that is consistent with prior reports (Heller, 1982; Jones \& O'Neal, 1985; Lederman \& Abbott, 1981). Subjects in both vision and touch conditions were highly accurate with the coarser stones. Touch was superior to vision, however, for the finer textures $(1,200-6,000$ grit $)$. Vision performed very poorly with the finer range of textures: sight was not adequate for the detection of relative smoothness, although touch yielded high accuracy.

The obtained superiority of touch was surprising, given the typical assumption that vision is the paramount spatial sense. It is possible, however, that touch subjects employed the vibratory sense to distinguish the finest textures. Phillips, Johnson, and Browne (1983) proposed that very fine textures may contain details that are too small to be resolved spatially, yet may be detected using "nonspatial," rate information. That this may have obtained in the present experiment is supported by the observation that subjects frequently used different scanning strategies when touching the smoothest surfaces. In addition to lateral scanning, they often pushed their index fingers against the surfaces in an attempt to discriminate them. This pushing behavior was infrequently observed with coarser stone surfaces, and may have represented an attempt to maximize vibratory, friction, or other texture cues. These speculations are not inconsistent with the report by Lederman, Loomis, and Williams (1982) that vibration may play little role in judgments of the roughness of metal gratings, since their experiment used a different range of stimuli. Thus, it is proposed that individuals may employ scanning strategies that permit vibratory or perhaps friction cues when attempting to discriminate the finest textures (e.g., 1,200-6,000 grit), but not necessarily for those that are relatively coarse ( $<1,000$ grit). Prior reports (Taylor \& Lederman, 1975) on the irrelevance of friction for tactual texture judgments used very different, and much coarser, surfaces. It is also possible that changes in friction could induce qualitative changes in perceived texture, yet not modify the magnitude of sensory impressions. Taylor and Lederman (1975) proposed that the relevant stimulus for perceived roughness is the static deformation of the skin. Although there is relatively little deformation of the skin when one touches 4,000 grit, 6,000 grit, or even smoother surfaces, skin deformation (or changes in skin deformation) could still contribute to smoothness perception. It is also possible, however, that different factors might be involved in judgments of especially fine and coarse surfaces. Future research will need to be directed toward clarification of the mechanisms underlying texture judgments for very smooth surfaces.

The obtained tactual superiority for texture perception helps to provide some clarification of the results of Experiment 1 . According to the modality adeptness hypothesis (Freides, 1974), observers would be expected to code information in the modality that is most appropriate, that is, most accurate. One would not expect visual imagery to provide a useful coding strategy when vision is no better than touch (for coarser surfaces) and can be less capable than touch in the discrimination of the smoothness of finer surfaces. These results are also consistent with recent work on the relative dominance of vision and touch in judgments of surface characteristics (Lederman, Thorne, \& Jones, 1986). Lederman et al. studied texture judgments using an intersensory discrepancy paradigm. They reported that vision dominates touch when subjects are instructed to judge spatial density; however, touch dominated vision when subjects were told to identify surface roughness. Lederman et al. argued that modality adeptness provides the basis for the relative weighting of visual or tactual cues to surface texture.

\section{GENERAL DISCUSSION}

Visual imagery is not necessary for texture perception and did not aid smoothness judgments in Experiment 1. This was shown by the lack of any differences between the sighted, late blind, and early blind. No differences appeared between active and passive texture perception, and the presence of motor activity did not serve to distinguish the sighted and the blind. If anything, the early blind performed slightly better than the sighted with active touch. Furthermore, the sense of touch was as capable as sight in judging the smoothness of relatively coarse surfaces, and much better than vision for relatively fine surfaces (Experiment 2). The adequacy of touch for texture perception explains the similar performance between the sighted and early blind, since visual recoding would not represent an efficient perceptual or cognitive strategy for tasks that are highly suited to the sense of touch.

The present results are inconsistent with the idea that touch is generally an inferior sense. There can be advantages to feeling surfaces over looking at them, especially when vision is limited to low contrast information or when surface textures are especially fine. This would be the case for an individual attempting to judge the smoothness of a wood or metal surface that is being sanded in preparation for finishing. Under these circumstances, touch has obvious advantages over vision. The detection of large textural features might be better achieved through sight. Microstructure, however, can be apprehended by the two senses with equal facility over a limited range of surface textures (e.g., 40-1,000 grit abrasives). There is clearly a range over which both senses probably acquire equivalent information about surface characteristics. Furthermore, just as there are textures that can be felt but not seen, there are surface textures that can be seen but not felt. There is a wealth of textural information that is available in paintings that derives from color and brightness, and this information is denied to the sense of touch.

The superiority of touch over vision for very fine textures is inconsistent with the idea that the skin senses always operate like "blurred vision,"'and are universally inferior to sight (Loomis, 1981). Active (or passive) movement can be used to enhance haptic performance 
(Lederman \& Klatzky, 1987). Most prior comparisons between the two senses of sight and touch have relied on rather artificial stimuli. They were generally constrained to two-dimensional, impoverished arrays, which were sometimes to the advantage of sight. Furthermore, many studies have provided severe temporal constraints, a procedure that handicaps the sense of touch. Future studies might well employ more varied, three-dimensional stimuli, with which the two senses are equally familiar. Touch can reveal excellent performance when one is asked to identify common objects and active movement is permitted (Klatzky, Lederman, \& Metzger, 1985).

The results of the present experiments are consistent with a theoretical position that recently has been presented by Lederman and Klatzky in a number of papers (Klatzky \& Lederman, in press; Klatzky, Lederman, \& Reed, 1987; Lederman \& Klatzky, 1987). It should be noted that the following discussion is speculative. Lederman and Klatzky argued that haptics does not always require mediation by visual images. They proposed that haptics may often provide optimal performance when individuals attempt to identify multidimensional stimuli, such as common three-dimensional objects (Klatzky et al., 1985) that vary along a number of substance-related dimensions. Touch may perform well in the apprehension of texture, hardness, thermal properties, and weight, all substancerelated dimensions; visual imagery may not be needed, and direct haptic encoding is likely for these "substance" qualities. However, vision may perform much better than touch in judging contour or shape (Heller, 1987). Touch seems rather poor at identifying two-dimensional patterns (other than braille) such as tangible graphics or pictorial representations (Magee \& Kennedy, 1980). Most people are relatively unfamiliar with the use of touch for the pickup of two-dimensional (structural) shape information. The familiarity factor cannot fully explain the difficulty of tactually perceiving raised-line drawings, because sighted observers may perform better than the early blind in tactual identification of raised-line drawings (Kennedy \& Fox, 1977). However, both the sighted and blind performed at low levels in the Kennedy and Fox study. Poor tactual performance with raised-line patterns could derive from the sequential nature of exploration and the consequent memory load (Klatzky \& Lederman, in press). Klatzky and Lederman also proposed that two-dimensional arrays are not ecologically valid for touch, and constitute impoverished displays. Clearly, touch is far better when exploring actual, solid objects with multiple substance cues. Furthermore, two-dimensional planar arrays force touch to rely on kinesthetic information, where error and distortion are common (Lederman, Klatzky, \& Barber, 1985). Visual imagery might be most likely to aid touch when the sighted individual touches familiar shapes (Juurmaa, 1967, 1973). Nonetheless, visual imagery is not necessary, according to Lederman and Klatzky (1987), for the tactual perception of surface structure.

Klatzky, Lederman, and Reed (1987) argued that different characteristics of objects are perceptually salient for the senses of vision and touch. They proposed that haptics is more oriented toward substance (i.e., texture; see Heller, 1982), whereas vision is more influenced by contour in sorting tasks. Moreover, they found that when subjects attempted to visualize objects they were sorting, their images included structural, contour information, but not texture.

In summary, the results of the present experiments suggest that visual imagery is not necessary for texture perception. Moreover, there were no indications of visual recoding in the late blind or sighted, inasmuch as the sighted, late blind, and early blind performed at equivalent levels. Finally, Experiment 2 demonstrated that touch and vision can perform similarly over a limited range of textural stimuli, but that touch holds advantages over sight for the finest surfaces. There are obviously circumstances in which touch may be deficient, and some congenitally blind persons may have difficulty. This may be the case for large-scale space. Surface microstructure, however, can be known by touch, and the blind need not suffer in this regard.

\section{REFERENCES}

Bailes, S. M., LAmbert, R. M. (1986). Cognitive aspects of haptic form recognition by blind and sighted subjects. British Journal of Psychology, 77, $451-458$.

Bitterman, M. E., \& Worchel, P. (1953). The phenomenal vertical and horizontal in blind and sighted subjects. American Journal of Psychology, 66, 598-602.

BjoRKMAN, M. (1967). Relations between intra-modal and cross-modal matching. Scandinavian Journal of Psychology, 8, 65-76.

Christian, J., Bickley, W., Tarka, M., \& Clayton, K. (1978). Measures of free recall of 900 English nouns: Correlations with imagery, concreteness, meaningfulness, and frequency. Memory \& Cognition, 6, 379-390.

Freides, D. (1974). Human information processing and sensory modality: Crossmodal functions, information complexity, memory, and deficit. Psychological Bulletin, 81, 284-310.

Gibson, J. J. (1962). Observations on active touch. Psychological Review, 69, 477-490.

Heller, M. A. (1980a). Reproduction of tactually perceived forms. Perceptual \& Motor Skills, 50, 943-946.

Heller, M. A. (1980b). Tactile retention: Reading with the skin. Perception \& Psychophysics, 27, 125-130.

Heller, M. A. (1982). Visual and tactual texture perception: Intersensory cooperation. Perception \& Psychophysics, 31, 339-344.

Heller, M. A. (1984). Active and passive touch: The influence of exploration time on form recognition. Journal of General Psychology, 110, 243-249.

Heller, M. A. (1985). Tactual perception of embossed Morse code and braille: The alliance of vision and touch. Perception, 14, 563-570.

HeLler, M. A. (1986a). Active and passive tactile braille recognition. Bulletin of the Psychonomic Society, 24, 201-202.

Heller, M. A. (1986b). Central and peripheral influences on tactual reading. Perception \& Psychophysics, 39, 197-204.

HeLler, M. A. (1987). The effect of orientation on visual and tactual braille recognition. Perception, 16, 291-298.

Heller, M. A., Boyd, M. E. (1984). Touching with a wand. Perceptual \& Motor Skills, 58, 390.

JoNES, B. (1975). Spatial perception in the blind. British Journal of Psychology, 66, 461-472.

JoNes, B., \& O'NeAL, S. (1985). Combining vision and touch in texture perception. Perception \& Psychophysics, 37, 66-72.

JuUrmaA, J. (1967). Ability structure and loss of vision. New York: American Foundation for the Blind.

JuUrmaA, J. (1973). Transposition in mental spatial manipulation: A 
theoretical analysis. American Foundation for the Blind Research Bulletin, 26, 87-134.

Kennedy, J. M., Fox, N. (1977). Pictures to see and pictures to touch. In D. Perkins \& B. Leondar (Eds.), The arts and cognition (pp. 118-135). Baltimore: J. Hopkins Press.

Klatzky, R. L., Lederman, S. J. (in press). The intelligent hand. In G. Bower (Ed.), The psychology of learning and motivation (Vol. 21). New York: Academic Press.

Klatzky, R. L., Lederman, S. J., \& Metzger, V. A. (1985). Identifying objects by touch: An expert system. Perception \& Psychophysics, 37, 299-302.

Klatzky, R. L., Lederman, S. J., \& Reed, C. (1987). There's more to touch than meets the eye: The salience of object attributes for haptics with and without vision. Journal of Experimental Psychology: General, 116, 356-369.

Krueger, L. E. (1982). Tactual perception in historical perspective: David Katz's world of touch. In W. Schiff \& E. Foulke (Eds.), Tactual perception: A sourcebook (pp. 1-54). New York: Cambridge University Press.

LAMB, G. D. (1983). Tactile discrimination of textured surfaces: Psychophysical performance measurements in humans. Journal of Physiology (London), 338, 551-565.

Lederman, S. J. (1981). The perception of surface roughness by active and passive touch. Bulletin of the Psychonomic Society, 18, 253-255.

Lederman, S. J. (1983). Tactual roughness perception: Spatial and temporal determinants. Canadian Journal of Psychology, 37, 498-511.

Lederman, S. J., \& AbBott, S. G. (1981). Texture perception: Studies of intersensory organization using a discrepancy paradigm and visual vs. tactual psychophysics. Journal of Experimental Psychology: $\mathrm{Hu}$ man Perception \& Performance, 7, 902-915.

LEDERMAN, S. J., \& KLATZKY, R. L. (1987). Hand movements: A window into haptic object recognition. Cognitive Psychology, 19, 342-368.

Lederman, S. J., Klatzky, R. L., Barber, P.O. (1985). Spatial and movement-based heuristics for encoding pattern information through touch. Journal of Experimental Psychology: General, 114, 33-49.

Lederman, S. J., Loomis, J. M., \& Williams, D. A. (1982). The role of vibration in the tactual perception of roughness. Perception \& Psychophysics, 32, 109-116.

Lederman, S. J., Thorne, G., Jones, B. (1986). Perception of texture by vision and touch: Multidimensionality and intersensory integration. Joumal of Experimental Psychology: Human Perception \& Performance, 12, 169-180.

LOOMIS, J. M. (1981). Tactile pattern perception. Perception, 10, 5-27.

MaGeE, L. E., KenNedy, J. M. (1980). Exploring pictures tactually. Nature, 283, 287-288.

MiLLAR, S. (1975). Spatial memory by blind and sighted children. British Journal of Psychology, 66, 449-459.

MillaR, S. (1976). Spatial representation by blind and sighted children. Joumal of Experimental Child Psychology, 21, 460-479.

Millar, S. (1978). Aspects of memory for information from touch and movement. In G. Gordon (Ed.), Active touch (pp. 215-227). Oxford: Pergammon Press.

Millar, S. (1985). The perception of complex patterns by touch. Perception, 14, 293-303.

Phillips, J. R., Johnson, K. O., \& Browne, H. M. (1983). A comparison of visual and two modes of tactual letter recognition. Perception \& Psychophysics, 34, 243-249.

PICK, H. L., JR. (1974). Visual coding of non-visual information. In R. B. MacLeod \& H. L. Pick, Jr. (Eds.), Perception: Essays in honor of James J. Gibson (pp. 153-165). Ithaca, NY: Cornell University Press.

STEvens, S. S., \& HARRIS, J. R. (1962). The scaling of subjective roughness and smoothness. Journal of Experimental Psychology, 64, 489-494.

TAYLOR, M. M., \& Lederman, S. J. (1975). Tactile roughness of grooved surfaces: A model and the effect of friction. Perception \& Psychophysics, 17, 28-36.

W ARREN, D. H. (1984). Blindness and early childhood development. New York: American Foundation for the Blind.

WELCH, R. B., WARREN, D. H. (1986). Intersensory interactions. In K. Boff, L. Kaufman, \& J. P. Thomas (Eds.), Handbook of perception and human performance. Vol. 1: Sensory processes. New York: Wiley.

Worchel, P. (1951). Space perception and orientation in the blind. Psychological Monographs, 65, 1-28.

\section{NOTES}

1. Although it would have been desirable to use independent groups for active and passive touch, it was not possible to locate enough earlyblind observers. It should be noted that Lederman (1983) reported identical performance for passive subjects in a repeated measures design and an additional group of subjects exposed to passive texture judgments.

2. An experiment was performed to compare the accuracy of making smoothness judgments and roughness judgments, since many researchers have asked individuals to judge the roughness of surface textures (Jones \& O'Neal, 1985; Lederman, 1981; Lederman \& Abbott, 1981). In a repeated measures design, sighted observers $(N=14)$ made judgments about the relative smoothness or roughness of abrasive surfaces. Half of the subjects first chose the smoothest of three abrasive surfaces and then chose the roughest surface on remaining trials; half of the subjects used the reverse sequence. The stimuli were similar to those of Experiment 1, but the subjects chose among three surfaces of adjacent grit value, as in an earlier study (Heller, 1982). Each observer had 14 roughness and 14 smoothness judgments. Mean number correct was very similar for judgments of smoothness $(M=11.1)$ and roughness $(M=11)(t<1)$. Haptic texture judgments were as accurate as in prior research (Heller, 1982). Mean roughness performance $(78.6 \%$ correct) was somewhat higher than previously reported by Jones and O'Neal (1985, Experiment 3; 66\% correct, difficulty level 1), despite greater task difficulty when choosing among three alternatives. This higher performance in the present experiment probably occurred because Jones and O'Neal timed their subjects, or because they painted their stimuli, or perhaps because they varied task difficulty using repeated measures. The active, sighted subjects in Experiment 1 performed at a slightly higher level in their two-alternative relative smoothness judgments $(82.9 \%$ correct).

3. Unlike prior comparisons of active and passive texture perception (Lederman, 1981, 1983), force was not equated in the present experiment for two reasons. First, an attempt was made to make exploration ecologically valid. In naturalistic, active exploration of surface texture, force is controlled by the observer (Gibson, 1962). Second, it was considered possible that the superiority of active touch might lay in the ability to self-regulate force. Very high or low force levels could yield subjective experiences. Moreover, objective experience of different textures might require disparate force levels. For example, coarse surfaces can feel smooth when explored with insufficient force levels.

4. The RLF subjects performed very much like the other early-blind individuals. The mean numbers of correct judgments overall for the RL.F, other early blind, and sighted controls were $40.75,41$, and 39.7 , respectively.

5. Finding high performance for touch in the present experiments is not inconsistent with Heller's (1982) suggestion that texture perception is normally multimodal, and that vision is often used for control of hand movements. The claim that perception is typically multimodal does not mean that the senses need always function in a cooperative manner.

6. The $250 / 800$ stimuli were chosen because no intermediate grit values were available. Performance was perfect in both vision and touch.

(Manuscript received August 17, 1987; revision accepted for publication July 27,1988 .) 